\title{
Frequency of Capsular Invasion and Prenephric Fat Infiltration in Renal Cell Carcinoma After Partial Nephrectomy
}

\section{Seyed Amin Mirsadeghi ${ }^{1}{ }^{(\mathbb{D})}$, Mohammad Soleimani², Amir-Hossein Khalili ${ }^{3}$, Abbas Basiri ${ }^{4}$, Majid Aliasgari ${ }^{2}$, Abolfazl Razzaghdoust ${ }^{5}$, Nasser Shakhssalim ${ }^{6 *}$}

1. Urologist, Urology and Nephrology Research Center, Shahid Labbafinejad Medical Center, Shahid Beheshti University of Medical Sciences, Tehran, Iran

2. Associate Professor, Department of Urology, Clinical Research Development Center, Shahid Modarres Hospital, Shahid Beheshti University of Medical Sciences, Tehran, Iran

3. Urologist, Department of Urology, Clinical Research Development Center, Shahid Modarres Hospital, Shahid Beheshti University of Medical Sciences, Tehran, Iran

4. Professor, Urology and Nephrology Research Center, Shahid Labbafinejad Medical Center, Shahid Beheshti University of Medical Sciences, Tehran, Iran

5. Cancer Researcher, Urology and Nephrology Research Center, Shahid Beheshti University of Medical Sciences, Tehran, Iran

6. Associate Professor, Urology and Nephrology Research Center, Shahid Labbafinejad Medical Center, Shahid Beheshti University of Medical Sciences, Tehran, Iran

\section{Article Information}

Article History

Received: $\quad$ 2019/03/31

Accepted: $\quad$ 2019/04/18

Available Online: 2019/09/16

JUR 2019; 3(1):05-12

DOI: 10.30699/jru.3.1.5

Use your device to scan and read the article online

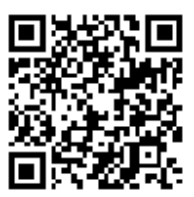

Corresponding Author

Nasser Shakhssalim Associate Professor, Urology and Nephrology Research Center, Shahid Labbafinejad Medical Center, Shahid Beheshti University of Medical Sciences, Tehran, Iran

Tel: $021-22567222$

Email:

slim456@yahoo.com

\section{Abstract}

Background \& Objective: Nowadays, partial nephrectomy (PN) has specific indications in renal tumors. There are challenges regarding the remaining and seeding of malignant cells after surgery due to increasing tendency to do laparoscopic PN (LPN) and consequently increased manipulation of the surrounding tumor tissue. The objective of this study was to investigate the frequency of renal capsule invasion (RCI) and perinephric fat infiltration (PFI) in patients with renal cell carcinoma (RCC) who had underwent PN.

Methods: Clinical data and pathologic samples of 101 patients who underwent PN and had RCC from 2011 to 2012 were elicited. Sixty one patients underwent LPN and 40 patients underwent open PN (OPN). All pathologic samples were reviewed by an uropathologist. Fuhrman nuclear grade, surgical margin and prevalence of RCI and PFI were also determined.

Results: The mean tumor size was $40.7 \mathrm{~mm}$ (range: $15 \mathrm{~mm}$ to $120 \mathrm{~mm}$ ). In all cases, the renal capsule and perinephric fat were left intact. Surgical margin was involved in four cases of LPN. Three patients had recurrence during follow up time (follow up durations were 12, 16, and 24 months for each). The fourth one was expired during 30 months follow up despite performing radical nephrectomy.

Conclusions: Based on the results obtained in this study, the probability of RCI and PFI is low and hence manipulating and removing the perinephric fat to achieve better exposure to tumor will not increase the risk of seeding malignant cells.

Keywords: Capsular involvement; Partial nephrectomy; Prenephric fat infiltration; Renal cell carcinoma

How to cite this article:

Mirsadeghi S A, Soleimani M, Khalili A, Basiri A, Aliasgari M, Razzaghdoust A et al. Frequency of Capsular Invasion and Prenephric Fat Infiltration in Renal Cell Carcinoma After Partial Nephrectomy. J Res Urol. 2019; 3 (1): 5-12 


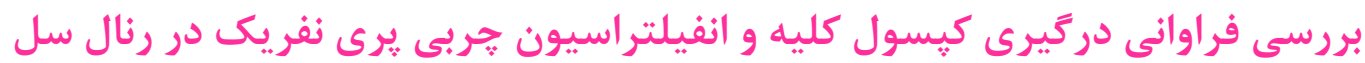
كارسينوما بعد از يارشيال نفر كتومى انفيلت

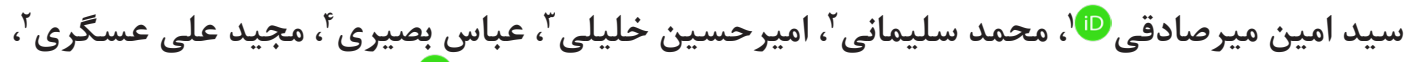

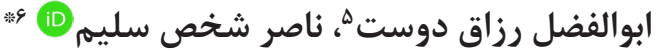

ا. ارولوزيست، مركز تحقيقات بيمارى هاى كليه و مجارى ادرارى، بيمارستان شهيد لبافى نزاد، دانشكاه علوم بزشكى شهيدبهشتى، تبهران، ايران

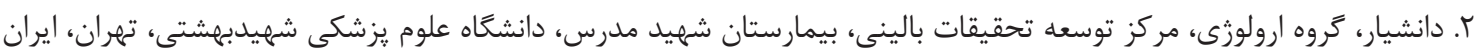

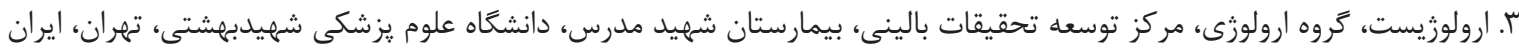

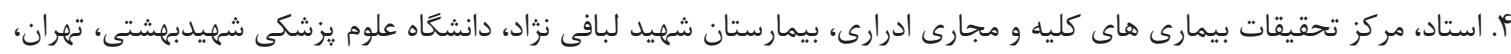

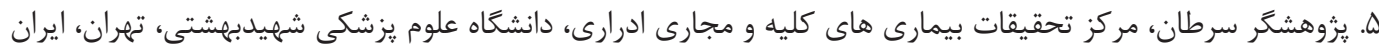

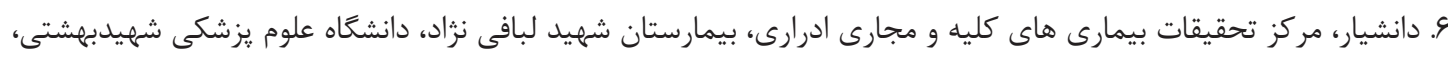

تهران، ايران

جكيده

زمينه و هدف: امروزه پِارشيال نفركتومى انديكاسيون ويزهاى در جراحى تومورهاى كليوى دارد. به دليل باريل

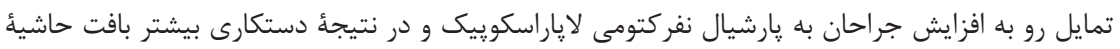

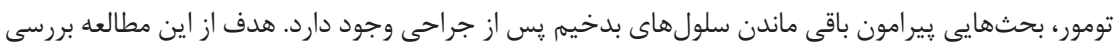

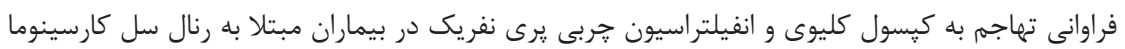

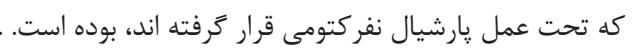

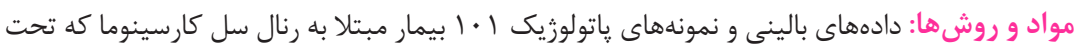

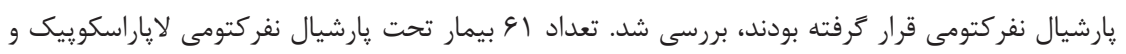

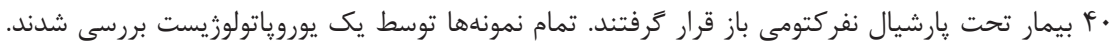

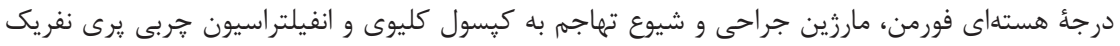

$$
\text { مشخص شد. }
$$

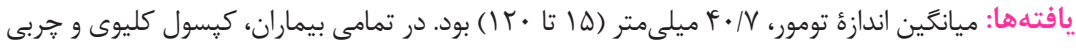

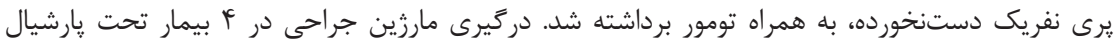

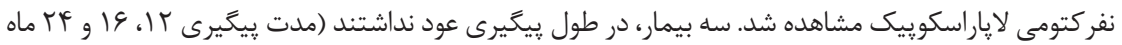

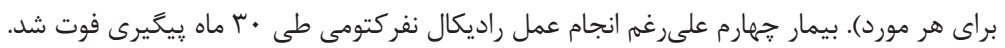

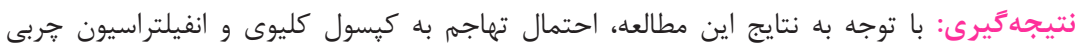

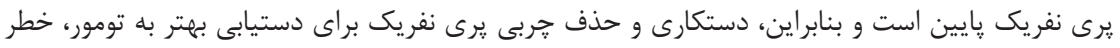

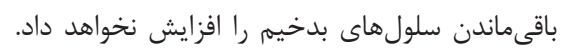
وازههاى كليدى: دركيرى كيسول، پارشيال نفركتومى، انفيلتراسيون خربى :برى نفريك، رنال سل كار سينوما
JUR 2019; 3(1):05-12

براى دانلود اين مقاله، كد زير را با موبايل خود دانود مقاله اسكن كنيد.

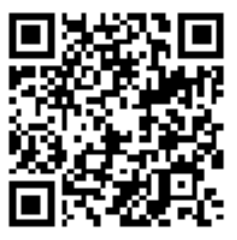

نويسندة مسئول: ناصر شخص سليه، استاديار، بخش اورولوزى، بيمارستان مركز طبى كودكان، دانشخاه علوم يزشكى تهران، تهران، ايران تلفن : Slim456@yahoo.com 


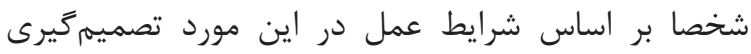

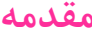

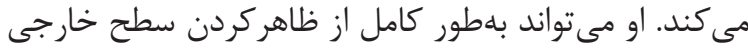

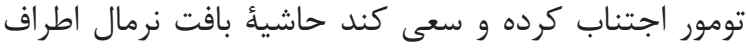

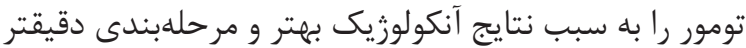

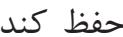

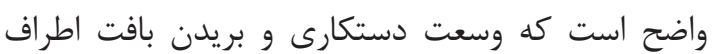

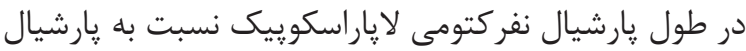

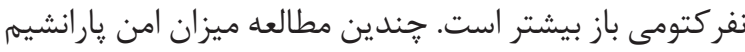

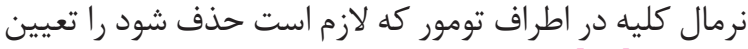

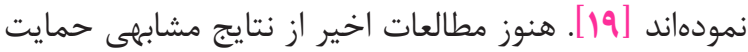

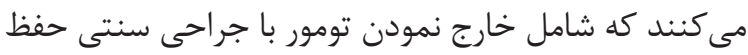

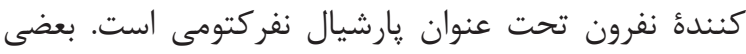

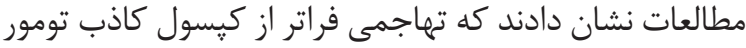

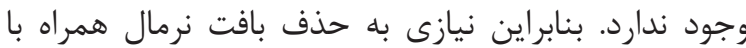

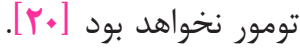

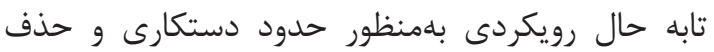

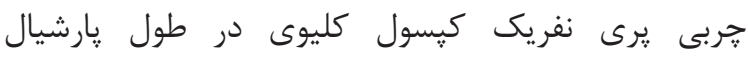

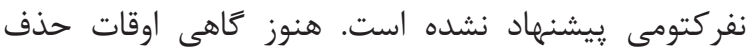

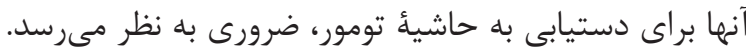

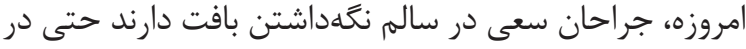

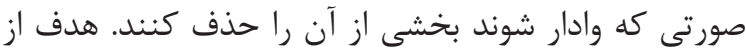

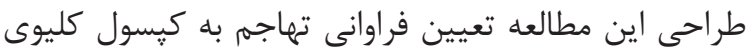

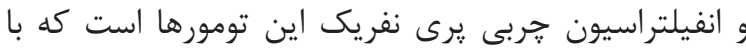

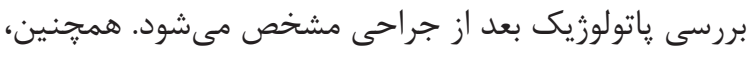

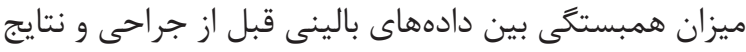
ياتولوزيك بعد از جراحى بررسى شدندي

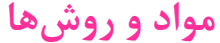

اين مطالعه بهوسيلة كميتأ اخلاق مركز تحقيقات

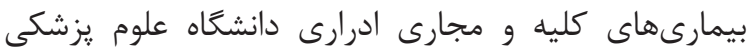

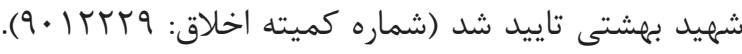

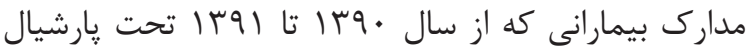

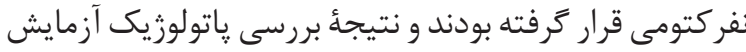

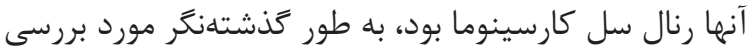

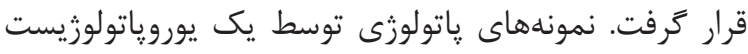

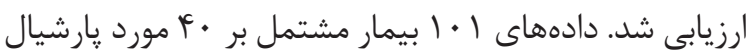

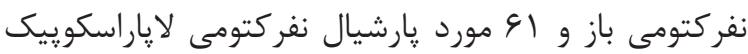

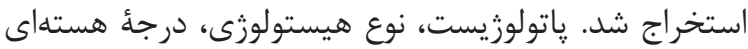

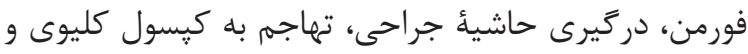

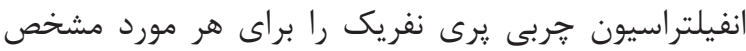

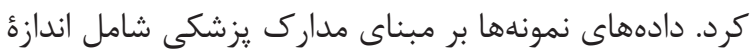

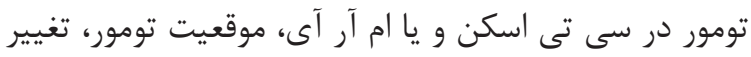

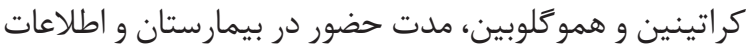

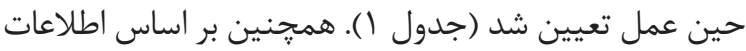

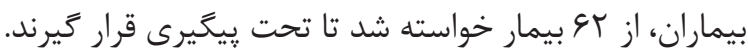

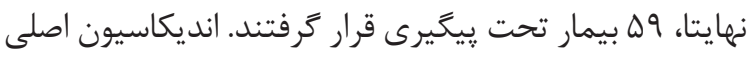

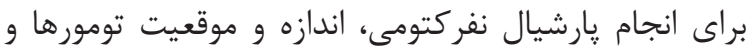

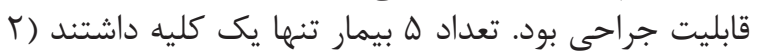




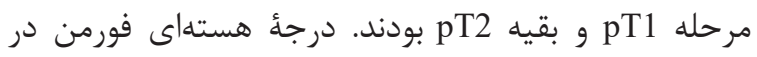

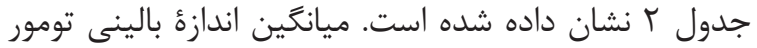

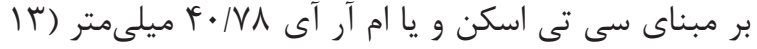

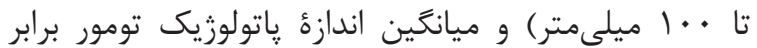

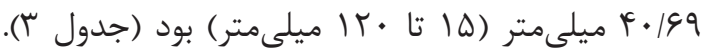

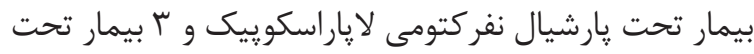

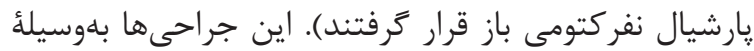

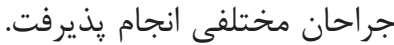

كافتهن

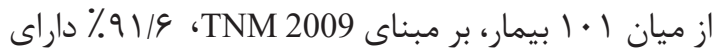

جدول ا. ويزّكى هاى بيماران

\begin{tabular}{|c|c|c|c|c|}
\hline $\mathrm{P}$ & كل & يارشيال نفر كتومى لايار اسكو ِييك & بارشيال نفر كتومى باز & \\
\hline & 1.1 & 91 & f. & تعداد جراحىها \\
\hline \multirow[t]{2}{*}{$.1 \cdot 1$} & $\Delta T / q \pm 1 F / r$ & $\mathcal{F} / \Lambda \pm I Y / \Lambda$ & $\Delta V / r \pm 1 \Delta / r$ & سن، سال \\
\hline & & & & جنس، تعداد (\%) \\
\hline \multirow{2}{*}{.199} & $9 \wedge(9 \vee / V)$ & rq $(9 \Delta)$ & rq $(V \cdot / V)$ & 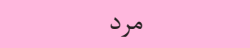 \\
\hline & r (Tr/V) & $r)(r \Delta)$ & $\mathbb{I r}(r q / r)$ & 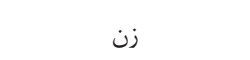 \\
\hline$\cdot / 49$ & $\Delta(F / q)$ & $r(\Psi / \Gamma)$ & $r(V / r)$ & كليه منفرد، تعداد (\%) \\
\hline $.1 \cdot 1$ & $\varphi \cdot / v \wedge \pm 1 \Lambda$ & $r q / 4 \pm 19 / V$ & $r \varepsilon / q \pm r q / q$ & اندازه بالينى، ميليمتر \\
\hline$\cdot / \Delta \Delta$ & $\Delta / \Lambda \pm r / V$ & $\Delta / V \pm r / r$ & $\varphi \pm r / r$ & اقامت در بيمارستان، روز \\
\hline$\cdot 1 \cdot \cdot 1$ & $\mid F r \pm \Delta r$ & $19 \cdot 19 \pm \Delta r$ & $\| V / F \pm F r / F$ & مدت جراحى، دقيقه \\
\hline r & $\cdot / I V$ & $\cdot / 1 \Delta$ & $\cdot / r$ & اختلاف كراتينين" \\
\hline$\cdot / r v$ & $1 / 4$ & $1 / 0$ & $1 / \pi$ & اختلاف هموكلوبين" \\
\hline$\cdot|r|$ & $T T(Y) / \Lambda)$ & $\|(1 / / 9)$ & $\|(T V / \Delta)$ & انتقال خون، تعداد (٪) \\
\hline
\end{tabular}

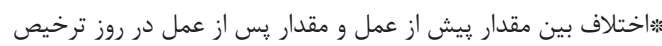

جدول r. درجةُ هستهاى فورمن تومورها

\begin{tabular}{|c|c|c|c|c|c|}
\hline \multirow{2}{*}{ كل } & \multicolumn{2}{|c|}{ نوع جراحى } & & & \\
\hline & يارشيال نفركتومى لاياراسكوِيك & يارشيال نفر كتومى باز & & & \\
\hline 9 & r & $\Delta$ & 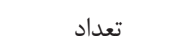 & & \\
\hline $11 / \Delta$ & $\Lambda / V$ & $\mid Q / 9$ & درصد در هر گروه & & \\
\hline $4 q$ & rT & iv & تعداد & & \\
\hline $9 T / 1$ & $99 / 9$ & $\Delta T / 1$ & درصد در هر كروه & & \\
\hline 19 & 1. & 9 & 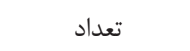 & & \\
\hline$r F / F$ & TI/V & $r \Lambda / 1$ & درصد در هر كروه & T & درجه بدحيمى \\
\hline 1 & . & 1 & 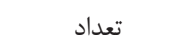 & & \\
\hline $1 / r$ & . & $r / 1$ & درصد در هر كروه & & \\
\hline vı & is & rt & 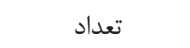 & & \\
\hline $1 \cdots$ & $1 \ldots$ & $1 \cdots$ & درصد در هر كروه & $\rho$ & \\
\hline
\end{tabular}


جدول r. اندازه هاتولوزيك تومورهاش

\begin{tabular}{|c|c|c|c|c|c|}
\hline \multirow{2}{*}{ كل } & \multicolumn{2}{|c|}{ نوع جراحى } & & & \\
\hline & يارشيال نفركتومى لاياراسكوييك & بارشيال نفركتومى باز & & & \\
\hline 90 & qr & rt & تعداد & \multirow{2}{*}{$\leq \mathrm{cmr}$} & \multirow{10}{*}{ اندازة تومور } \\
\hline $9 N / 4$ & Vब|A & $\Delta g / \mathcal{F}$ & درصد در هر تروه & & \\
\hline tr & 11 & 11 & تعداد & \multirow{2}{*}{$>\mathrm{F}$ تا $\leq \mathrm{cm} v$} & \\
\hline$r \mu / T$ & $19 / 9$ & TAN & درصد در هر تروه & & \\
\hline r & 1 & r & تعداد & \multirow{2}{*}{$>\vee \mathrm{V}$ L $\leq \mathrm{cm})$. } & \\
\hline$F / T$ & $1 / 1$ & $V / V$ & درصد در هر تروه & & \\
\hline f & 1 & r & تعداد & \multirow{2}{*}{$>\mathrm{cml}$. } & \\
\hline$f / T$ & $1 / 1$ & $V / V$ & درصد در هر تروه & & \\
\hline $9 \Delta$ & $\Delta \varphi$ & rq & تعداد & \multirow{2}{*}{ كل } & \\
\hline $1 \cdots$ & $1 \ldots$ & $1 \ldots$ & درصد در هر گروه & & \\
\hline
\end{tabular}

\section{بحث و نتيجه كيرى}

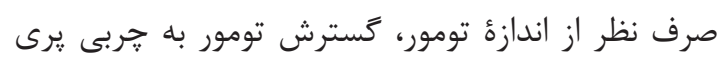

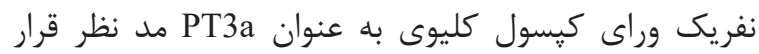

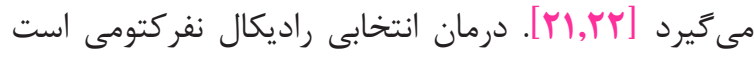

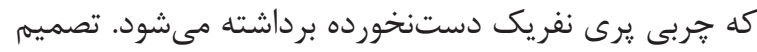

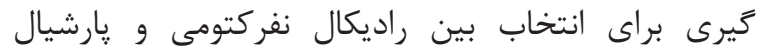

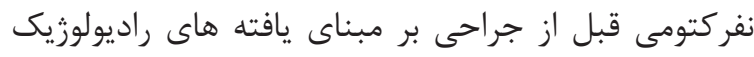

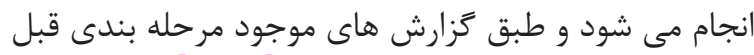

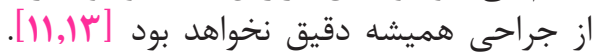

وجود حداقل 1 ميليمتر پارانشيم نرمال اطراف كيسول

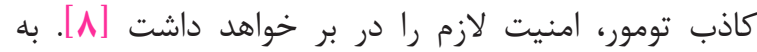

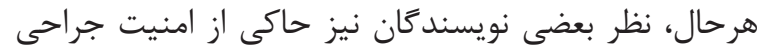

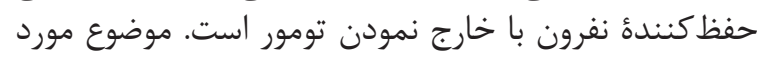

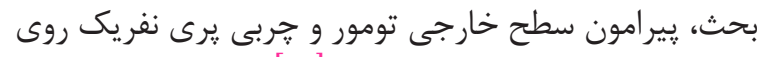

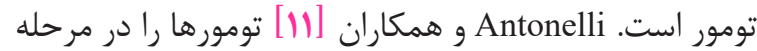

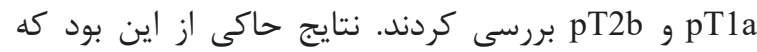

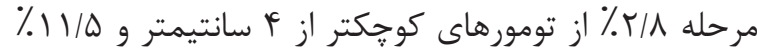

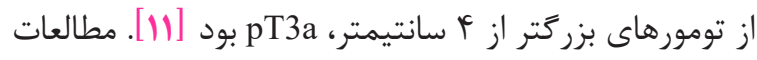

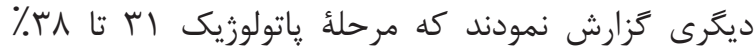

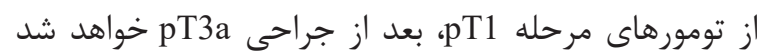

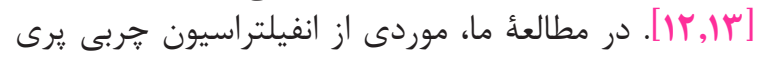

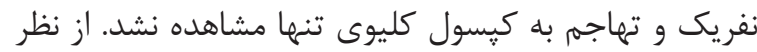

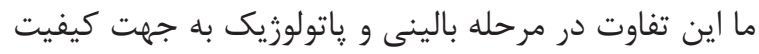

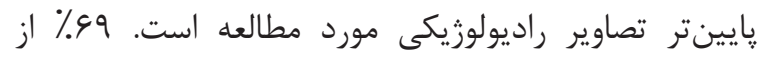

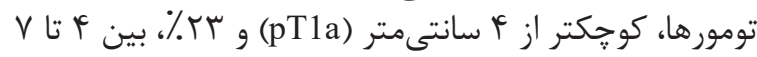

موردى با انفيلتراسيون خربى ترى نفريك و تهبو تهاجم به

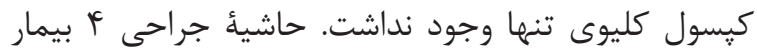

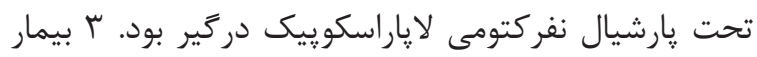

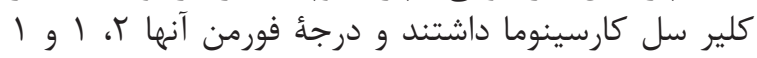

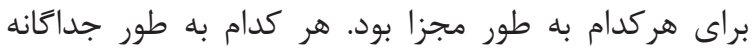

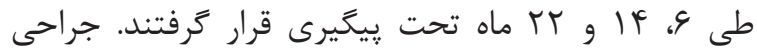

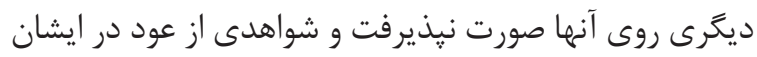

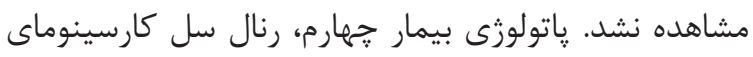

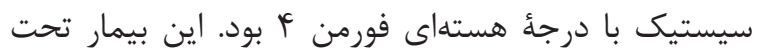
عمل راديكال نفركتومى باز قرار ترفتئ.

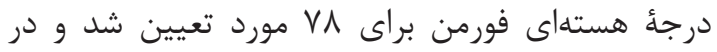

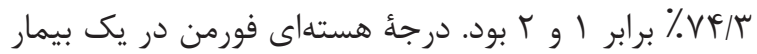

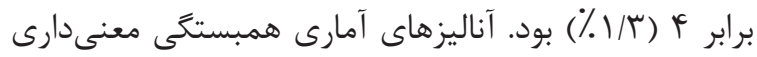

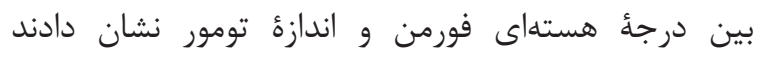

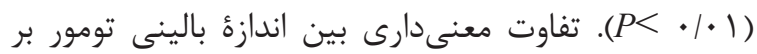

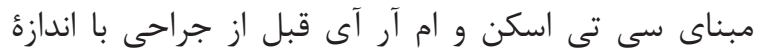

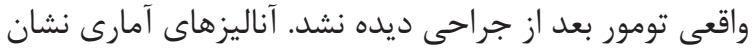

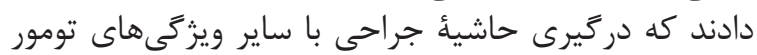
همبستكى نداشت.

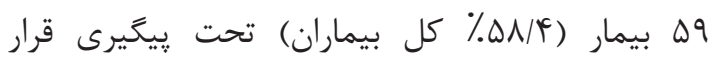

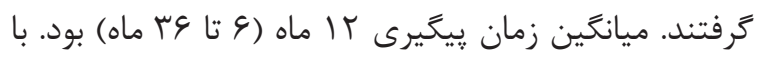

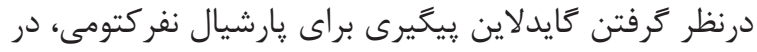

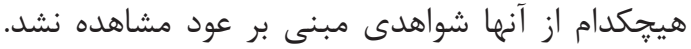




\section{نفريك يايين است.}

در اين مطالعه موردى از تهاجم به كيسول كليوى تنها

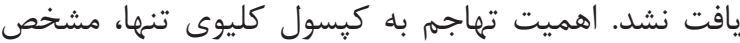

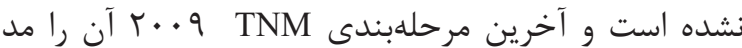

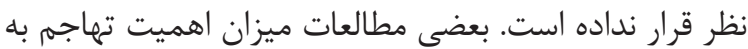

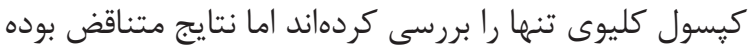

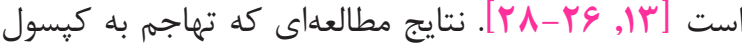
كليوى را تنها در يارشيال نفركتومى بررسى كرد، نشان مان داد

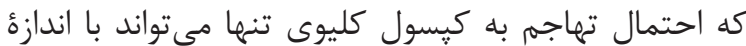

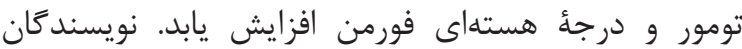

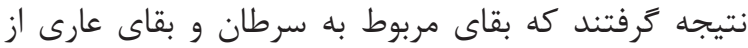

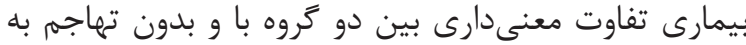

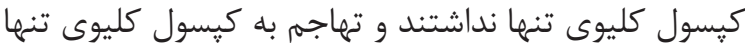

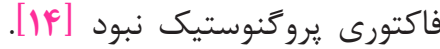

تنتايج اين مطالعه نشان داد كه تهاجم به كيسول كليوى

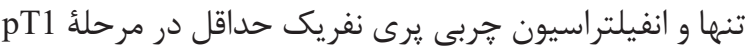

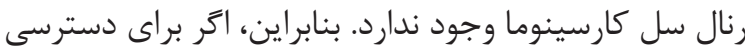

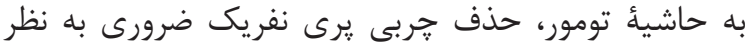

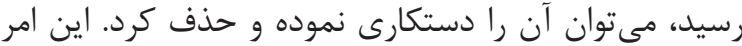

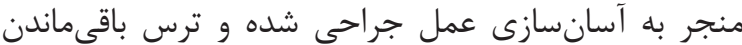

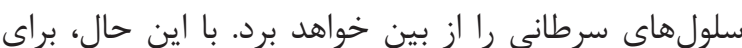

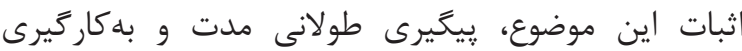

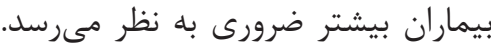

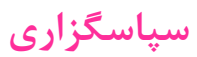

اين مطالعه با حمايت مركز تحقيقات بيمارىهاى كليه

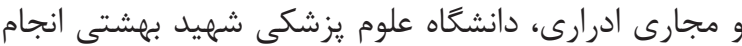

$$
\text { تعارض در منافع }
$$

بين نويسند

\section{References}

1. McKiernan J, Yossepowitch O, Kattan MW, Simmons R, Motzer RJ, Reuter VE, et al. Partial nephrectomy for renal cortical tumors: pathologic findings and impact on outcome. Urology. 2002;60(6):1003-9.

2. Becker F, Siemer S, Humke U, Hack M, Ziegler M, Stöckle M. Elective nephron sparing surgery should become standard treatment for small unilateral renal cell carcinoma: long-term survival data of 216 patients. European urology. 2006;49(2):30813.

3. Delakas D, Karyotis I, Daskalopoulos G, Terhorst B, Lymberopoulos S, Cranidis A. Nephron-sparing surgery for localized renal cell carcinoma with a normal contralat-

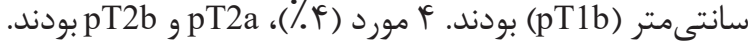
اين مطالعات ممكن است ريشنهماد كنند كه تصميمثيرى

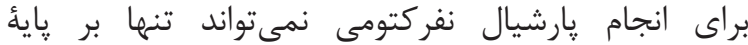

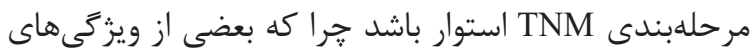

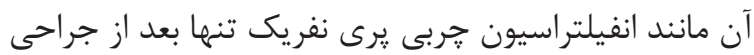

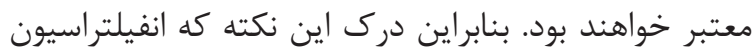

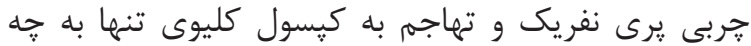
مقدار در مورد يارشيال نفركتومى نقش حياتى دارند، حائز

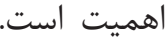

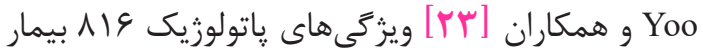

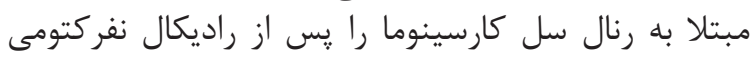

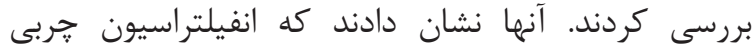

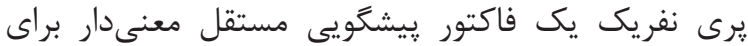

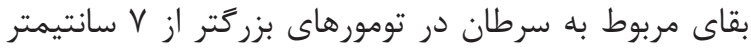

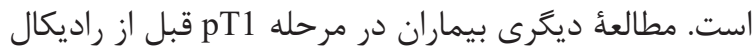

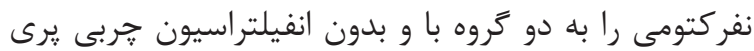

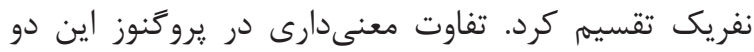

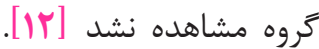

كزارشاتى هم وجود دارد مبنى بر اين كه اندازه تومور

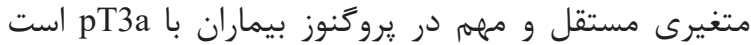

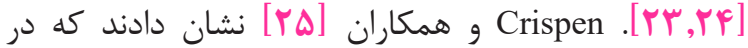

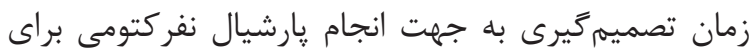

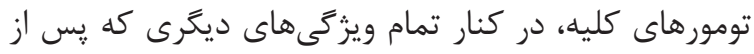

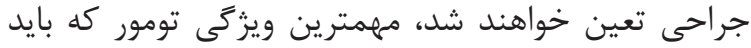

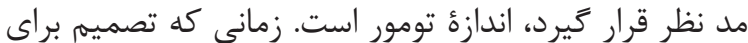

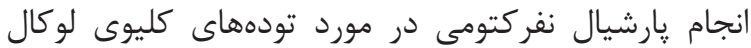

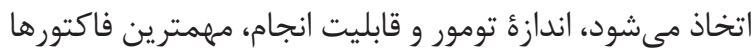

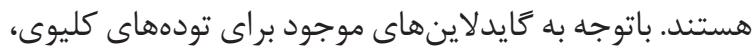

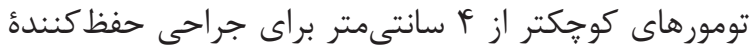

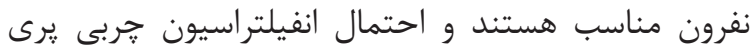

eral kidney: a European three-center experience. Urology. 2002;60(6):998-1002.

4. Gill IS, Kavoussi LR, Lane BR, Blute ML, Babineau D, Colombo JR, et al. Comparison of 1,800 laparoscopic and open partial nephrectomies for single renal tumors. The Journal of urology. 2007;178(1):41-6.

5. Raz O, Mendlovic S, Shilo Y, Leibovici D, Sandbank J, Lindner A, et al. Positive surgical margins with renal cell carcinoma have a limited influence on long-term oncological outcomes of nephron sparing surgery. Urology. 2010;75(2):277-80.

6. Link RE, Bhayani SB, Allaf ME, Varkarakis I, Inagaki T, Rogers C, et al. Exploring the learning curve, pathological outcomes and perioperative morbidity 
of laparoscopic partial nephrectomy performed for renal mass. The Journal of urology. 2005;173(5):1690-4.

7. Thompson RH, Siddiqui S, Lohse CM, Leibovich BC, Russo P, Blute ML. Partial versus radical nephrectomy for 4 to $7 \mathrm{~cm}$ renal cortical tumors. The Journal of urology. 2009;182(6):2601-6.

8. Margulis V, Tamboli P, Jacobsohn KM, Swanson DA, Wood CG. Oncological efficacy and safety of nephron-sparing surgery for selected patients with locally advanced renal cell carcinoma. BJU international. 2007;100(6):1235-9.

9. Minervini A, di Cristofano C, Lapini A, Marchi M, Lanzi F, Giubilei G, et al. Histopathologic analysis of peritumoral pseudocapsule and surgical margin status after tumor enucleation for renal cell carcinoma. european urology. 2009;55(6):1410-8.

10. Ljungberg B, Cowan NC, Hanbury DC, Hora M, Kuczyk MA, Merseburger AS, et al. EAU guidelines on renal cell carcinoma: the 2010 update. European urology. 2010;58(3):398-406.

11. Antonelli A, Cozzoli A, Nicolai M, Zani D, Zanotelli T, Perucchini L, et al. Nephron-sparing surgery versus radical nephrectomy in the treatment of intracapsular renal cell carcinoma up to $7 \mathrm{~cm}$. european urology. 2008;53(4):803-9.

12. Roberts WW, Bhayani SB, Allaf ME, Chan TY, Kavoussi LR, Jarrett TW. Pathological stage does not alter the prognosis for renal lesions determined to be stage $\mathrm{T} 1$ by computerized tomography. The Journal of urology. 2005;173(3):713-5.

13. Hsu RM, Chan DY, Siegelman SS. Small renal cell carcinomas: correlation of size with tumor stage, nuclear grade, and histologic subtype. American Journal of Roentgenology. 2004;182(3):551-7.

14. Rouach Y, Delongchamps N, Timsit MO, Verkarre V, Fontaine E, Peyromaure M, et al. Capsular involvement in patients undergoing partial nephrectomy for localized renal cell carcinoma: an adverse pathological finding? BJU international. 2010;105(5):616-9.
15. Margulis V, Tamboli P, Matin SF, Meisner M, Swanson DA, Wood CG. Redefining pT3 renal cell carcinoma in the modern era. Cancer. 2007;109(12):2439-44.

16. Karakiewicz PI, Lewinshtein DJ, Chun FK-H, Briganti A, Guille F, Perrotte P, et al. Tumor size improves the accuracy of TNM predictions in patients with renal cancer. European urology. 2006;50(3):521-9.

17. Yossepowitch $\mathrm{O}$, Thompson RH, Leibovich BC, Eggener SE, Pettus JA, Kwon $E D$, et al. Positive surgical margins at partial nephrectomy: predictors and oncological outcomes. The Journal of urology. 2008;179(6):2158-63.

18. Bensalah K, Pantuck AJ, Rioux-Leclercq N, Thuret R, Montorsi F, Karakiewicz PI, et al. Positive surgical margin appears to have negligible impact on survival of renal cell carcinomas treated by nephron-sparing surgery. European urology. 2010;57(3):46673.

19. Li Q-L, Guan H-W, Zhang Q-P, Zhang L-Z, Wang F-P, Liu Y-J. Optimal margin in nephron-sparing surgery for renal cell carcinoma $4 \mathrm{~cm}$ or less. European urology. 2003;44(4):448-51.

20. Van Poppel H, Joniau S. How important are surgical margins in nephron-sparing surgery? european urology supplements. 2007;6(8):533-9.

21. Bedke J, Buse S, Pritsch M, Macher-Goeppinger S, Schirmacher P, Haferkamp A, et al. Perinephric and renal sinus fat infiltration in pT3a renal cell carcinoma: possible prognostic differences. BJU international. 2009;103(10):1349-54.

22. Bertini R, Roscigno M, Freschi M, Strada E, Petralia G, Pasta A, et al. Renal sinus fat invasion in pT3a clear cell renal cell carcinoma affects outcomes of patients without nodal involvement or distant metastases. The Journal of urology. 2009;181(5):202732.

23. Yoo C, Song C, Hong JH, Kim C-S, Ahn $\mathrm{H}$. Prognostic significance of perinephric fat infiltration and tumor size in renal cell carcinoma. The Journal of urology. 2008;180(2):486-91. 
24. Murphy AM, Gilbert SM, Katz AE, Goluboff ET, Sawczuk IS, Olsson CA, et al. Re-evaluation of the Tumour-Node-Metastasis staging of locally advanced renal cortical tumours: absolute size (T2) is more significant than renal capsular invasion (T3a). BJU international. 2005;95(1):27-30.

25. Crispen PL, Boorjian SA, Lohse CM, Sebo TS, Cheville JC, Blute ML, et al. Outcomes following partial nephrectomy by tumor size. The Journal of urology. 2008;180(5):1912-7.

26. Cho H-J, Kim SJ, Ha U-S, Hong S-H, Kim
JC, Choi Y-J, et al. Prognostic value of capsular invasion for localized clear-cell renal cell carcinoma. European urology. 2009;56(6):1006-12.

27. Süer E, Ergün G, Baltacı S, Bedük Y. Does renal capsular invasion have any prognostic value in localized renal cell carcinoma? The Journal of urology. 2008;180(1):68-71.

28. Jeong IG, Jeong CW, Hong SK, Kwak C, Lee E, Lee SE. Prognostic implication of capsular invasion without perinephric fat infiltration in localized renal cell carcinoma. Urology. 2006;67(4):709-12. 